\title{
Diketopiperazines, inhibitors of sterol $O$-acyltransferase, produced by a marine-derived Nocardiopsis sp. KM2-16
}

\author{
Keisuke Kobayashi ${ }^{1}$, Takashi Fukuda ${ }^{1}$, Takeshi Terahara ${ }^{2}$, Enjuro Harunari ${ }^{2}$, Chiaki Imada ${ }^{2}$ and \\ Hiroshi Tomoda ${ }^{1}$
}

The Journal of Antibiotics (2015) 68, 638-641; doi:10.1038/ja.2015.38; published online 22 April 2015

Sterol O-acyltransferase (SOAT, also known as acyl-CoA:cholesterol acyltransferase (ACAT), EC 2.4.1.26), an endoplasmic reticulum (ER) membrane protein, catalyzes the synthesis of cholesteryl ester (CE) from free cholesterol and long-chain fatty acyl-CoA. SOAT has been postulated as a target for modulation by a new type of antiatherosclerotic agent. Recent molecular biological studies revealed the existence in mammals of two different SOAT isozymes, SOAT1 and SOAT2. ${ }^{1-4}$ SOAT1-selective inhibition may cause detrimental effects, ${ }^{5-7}$ whereas SOAT2-selective inhibition has consistently shown antiatherosclerotic activity. ${ }^{8,9}$ Therefore, it is important to determine the selectivity of inhibitors toward the two SOAT isozymes for development as new antiatherosclerosis agents. Our group has focused on the discovery of SOAT2-selective inhibitors of microbial origin in cell-based assay or an enzyme assay using microsomes prepared from SOAT2-expressing Chinese hamster ovary $(\mathrm{CHO})$ cells. During the course of our screening program, two diketopiperazines, 1 and amauromine $^{10}$ (2) (Figure 1), were isolated as SOAT2 inhibitors from the culture broth of actinomycete strain Nocardiopsis sp. KM2-16. Amauromine was originally isolated as a vasodilator from the culture broth of the fungus Amauroascus sp. Yin et al. ${ }^{11}$ reported that 1 was produced by bioconversion from cyclo-L-tryptophan-L-tryptophan using two recombinant enzymes involved in acetylaszonalenin biosynthesis. ${ }^{12}$ Thus, 2 and structurally related acetylaszonalenin were fungal secondary metabolites. In this study, we showed that $\mathbf{1}$ and $\mathbf{2}$ were isolated as actinomycete secondary metabolites and that 2 selectively inhibited SOAT2 activity.

The strain KM2-16 was isolated from sea sediments collected off Iriomote Island in Okinawa, Japan in 2012. In a BLAST search, the $16 \mathrm{~S}$ rRNA sequence of the strain KM2-16 indicated that it could be considered to belong to the actinomycete genus Nocardiopsis. The strain was inoculated into a 500-ml Erlenmeyer flask containing $100 \mathrm{ml}$ of production medium $(1.0 \%$ starch, $0.40 \%$ yeast extract, $0.20 \%$ peptone, $0.10 \% \mathrm{CaCO}_{3}, 0.010 \% \mathrm{KBr}, 0.0040 \%$ $\mathrm{Fe}_{2}\left(\mathrm{SO}_{4}\right)_{3} \bullet \mathrm{nH}_{2} \mathrm{O}, 100 \mathrm{ml}$ of natural seawater). Fermentation was carried out at $27^{\circ} \mathrm{C}$ for 11 days under shaking conditions (180 r.p.m.). The culture broth $(100 \mathrm{ml} \times 3)$ was extracted with acetone $(300 \mathrm{ml})$. This extract was concentrated and extracted with EtOAc to yield the crude extracts $(42 \mathrm{mg})$, which was purified by HPLC using a PEGASIL ODS column $\left(10 \times 250 \mathrm{~mm}^{2}\right.$, Senshu Scientific Co., Tokyo, Japan under the following conditions: solvent, a 30-min linear gradient from 50 to $85 \% \mathrm{CH}_{3} \mathrm{CN}$; flow rate, $3.0 \mathrm{ml} \mathrm{min}^{-1}$; detection, UV at $285 \mathrm{~nm}$. Compounds 1 and 2 were eluted as peaks with retention times of 14 and $29 \mathrm{~min}$, respectively. Each peak was collected and concentrated to yield pure $\mathbf{1}(8.6 \mathrm{mg})$ and $\mathbf{2}(4.6 \mathrm{mg})$ as colorless solids. Interestingly, $\mathbf{1}$ and 2 were produced in the seawater-supplemented medium, whereas almost no production was observed in an analogous medium made with distilled water.

The physico-chemical properties of $\mathbf{1}$ and $\mathbf{2}$ are summarized in Table 1. The molecular formulas of $\mathbf{1}$ and $\mathbf{2}$ were determined to be $\mathrm{C}_{27} \mathrm{H}_{28} \mathrm{~N}_{4} \mathrm{O}_{2}$ and $\mathrm{C}_{32} \mathrm{H}_{36} \mathrm{~N}_{4} \mathrm{O}_{2}$ on the basis of HR-ESI-MS measurement, respectively. From ${ }^{1} \mathrm{H}$ and ${ }^{13} \mathrm{C}$ NMR and specific rotation, 2 was identified as amauromine previously reported as a fungal vasodilator. ${ }^{10}$ Compound 1 had absorption maxima at 210, 219, 244, 282 and $290 \mathrm{~nm}$ in the UV spectrum. The IR absorption maxima of 1 at 3276 and $1664 \mathrm{~cm}^{-1}$ suggested the presence of amino and carbonyl moieties, respectively. Although 1 appeared to be a known compound reported by Yin et al., ${ }^{11}$ the structural determination has not been described in detail. The structure of 1 was mainly elucidated by analysis of NMR spectra, including $2 \mathrm{D}$ NMR. The ${ }^{13} \mathrm{C}$ NMR spectrum (in $\mathrm{CDCl}_{3}$ ) showed 27 resolved signals, which were classified into two methyl carbons, two $s p^{3}$ methylene carbons, three $s p^{3}$ methine carbons, one $s p^{2}$ methylene carbon, $10 s p^{2}$ methine carbons and 9 quaternary carbons, including two carbonyl carbons. The connectivity of proton and carbon atoms was established by the HMQC spectrum, as shown in Table 2. Analysis of the ${ }^{1} \mathrm{H}-{ }^{1} \mathrm{H}$ COSY spectrum gave the 7 partial structures I (NH-1 to C-2), II (C-4 to C-7), III (C-10 to C-11), IV (C-14 to C-17), V (C-19 to NH-20), VI (C-22 to C-25) and VII $\left(\mathrm{C}-1^{\prime}\right.$ to $\left.\mathrm{C}-2^{\prime}\right)$ drawn with the bold lines in Figure 2 . The ${ }^{1} \mathrm{H}^{-13} \mathrm{C}$ long-

${ }^{1}$ Graduate School of Pharmaceutical Sciences, Kitasato University, Tokyo, Japan and ${ }^{2}$ Graduate School of Marine Science and Technology, Tokyo University of Marine Science and Technology, Tokyo, Japan

Correspondence: Professor H Tomoda, Graduate School of Pharmaceutical Sciences, Kitasato University, 5-9-1 Shirokane, Minato-ku, Tokyo 108-8641, Japan. E-mail: tomodah@pharm.kitasato-u.ac.jp

Received 16 February 2015; revised 3 March 2015; accepted 16 March 2015; published online 22 April 2015 
<smiles>C=CC(C)(C)[C@@]12C[C@H]3C(=O)N[C@@H](Cc4c[nH]c5ccccc45)C(=O)N3[C@H]1Nc1cccc(C)c12</smiles>

1<smiles>C=CC(C)(C)[C@@]12C[C@H]3C(=O)N4[C@H](Nc5ccccc53)C(=O)N3[C@H]1C[C@]3(C(C)(C)C=C)c1ccccc1N[C@H]42</smiles>

2<smiles></smiles>

Figure 1 Structures of 1 , amauromine (2) and gypsetin (3).

Table 1 Physico-chemical properties of 1 and 2

\begin{tabular}{lll}
\hline & $\mathbf{1}$ & $\mathbf{2}$ \\
\hline Appearance & Colorless solid & Colorless solid \\
{$[\alpha]_{D}^{24.1}(\mathrm{c}=0.1, \mathrm{MeOH})$} & -182.9 & -558.7 \\
Molecular weight & 440 & 508 \\
Melecular formula & $\mathrm{C}_{27} \mathrm{H}_{28} \mathrm{~N}_{4} \mathrm{O}_{2}$ & $\mathrm{C}_{32} \mathrm{H}_{36} \mathrm{~N}_{4} \mathrm{O}_{2}$ \\
& & \\
HR-ESI-MS (m/z) & & \\
$\quad$ Calcd & $463.2110(\mathrm{M}+\mathrm{Na})^{+}$ & $509.2917(\mathrm{M}+\mathrm{H})^{+}$ \\
$\quad$ Found & $463.2107(\mathrm{M}+\mathrm{Na})^{+}$ & $509.2913(\mathrm{M}+\mathrm{H})^{+}$ \\
UV $\lambda_{\operatorname{mex}}^{\mathrm{MeOH}}(\log \varepsilon)$ & $210(3.0), 219(3.0)$, & $208(3.1), 244(2.5)$, \\
& $244(2.3)$ & $300(2.1)$ \\
& $282(2.2), 290(2.2)$ & \\
IR $\nu_{\max }^{\mathrm{KBr}} \mathrm{cm}-1$ & $3276,2970,1664$, & $3386,2972,1661$, \\
& 1451,1317 & 1462,1423 \\
$\mathrm{CD}(\mathrm{MeOH}) \lambda \mathrm{nm}$ & $220(3.7), 245(-5.6)$, & $222(-0.37), 244(-4.8)$, \\
$(\mathrm{Mol} . \mathrm{CD})$ & $272(-1.7), 300(-2.8)$ & $266(-0.17), 301(-1.0)$ \\
\hline
\end{tabular}

range couplings of ${ }^{2} J$ and ${ }^{3} J$ observed in the HMBC experiments gave the following information. (1) The cross-peaks were observed from $1-\mathrm{NH}(\delta 5.06)$ to C-3 ( $\delta$ 61.6) and C-9 ( $\delta 128.9)$, from $2-\mathrm{H}(\delta 5.55)$ to C-8 ( $\delta$ 149.9), C-9, C-11 ( $\delta$ 59.0) and C-13 ( $\delta$ 166.0), from 4-H $(\delta$ $7.14)$ to $\mathrm{C}-3$ and $\mathrm{C}-8$, from $5-\mathrm{H}(\delta 6.76)$ to $\mathrm{C}-9$, from $6-\mathrm{H}(\delta 7.11)$ to C-8, from 7-H ( $\delta 6.61)$ to C-9, from $10-\mathrm{H}_{2}(\delta 2.42,2.51)$ to C-3, C-9 and $\mathrm{C}-16$ ( $\delta 168.9)$, from $11-\mathrm{H}(\delta 3.91)$ to $\mathrm{C}-10$ and $\mathrm{C}-16$, from $14-\mathrm{H}$ ( $\delta$ 4.30) to C-13, and from 15-NH ( $\delta 5.69)$ to C-11, C-13, C-14, C-16 and $\mathrm{C}-17$ (27.0), suggesting the presence of 6-, 5-, 5- and 6-membered ring systems (Part A), including indoline and diketopiperazine rings, which contained the partial structures I, II, III and IV. (2) The crosspeaks were observed from $19-\mathrm{H}(\delta$ 7.08) to C-18 ( $\delta$ 109.7), C-21 ( $\delta$ 136.6) and C-26 ( $\delta$ 126.6), from NH-20 ( $\delta$ 8.19) to C-18, C-21 and C-26, from $22-\mathrm{H}(\delta$ 7.38) to C-26, from $\mathrm{H}-23$ ( $\delta$ 7.22) to C-21, from $24-\mathrm{H}(\delta 7.12)$ to $\mathrm{C}-26$ and from $25-\mathrm{H}(\delta 7.55)$ to $\mathrm{C}-18, \mathrm{C}-21$ and
C-26, suggesting the presence of the indole ring (Part B) containing the partial structures IV and V. (3) The cross-peaks were observed from $1^{\prime}-\mathrm{H}_{2}(\delta 5.08,5.12)$ to $\mathrm{C}-3^{\prime}(\delta 40.8)$, from $2^{\prime}-\mathrm{H}(\delta 5.97)$ to $\mathrm{C}-3$,

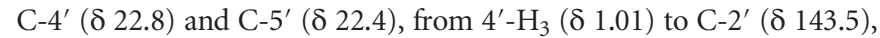
$\mathrm{C}-3^{\prime}$ and $\mathrm{C}-5^{\prime}$ and from $5^{\prime}-\mathrm{H}_{3}(\delta 1.11)$ to $\mathrm{C}-2^{\prime}, \mathrm{C}-3^{\prime}$ and $\mathrm{C}-4^{\prime}$, suggesting the presence of the prenyl moiety (Part C) containing the partial structure VII. Finally, (4) the cross-peaks from $17-\mathrm{H}_{2}$ $(\delta 2.97,3.74)$ to $\mathrm{C}-19(\delta 123.2)$ and $\mathrm{C}-26$, from $19-\mathrm{H}$ to $\mathrm{C}-17$, from $2-\mathrm{H}$ and $10-\mathrm{H}_{2}$ to $\mathrm{C}-3^{\prime}$ and from $2^{\prime}-\mathrm{H}, 4^{\prime}-\mathrm{H}_{3}$ and $5^{\prime}-\mathrm{H}_{3}$ to $\mathrm{C}-3$ indicated that Part A is attached to Parts B and C, as shown in Figure 2. The structure satisfied the degrees of unsaturation and the molecular formula.

The relative configurations of C-2, C-3, C-11 and C-14 were elucidated by NOE experiments. As shown in Figure 3, the cross-peaks between $2-\mathrm{H}$ and $4^{\prime}-\mathrm{H}_{3} / 5^{\prime}-\mathrm{H}_{3}$ proved the relative configurations, $2 S^{*}$ and $3 R^{*}$. Furthermore, the correlation between $\mathrm{H}-11$ and $\mathrm{H}-14$ proved the relative configurations, $11 S^{*}$ and $14 R^{*}$. As shown in Table 1 , the CD spectra of 1 showed positive Cotton effects at 272 and $220 \mathrm{~nm}$ and negative Cotton effects at 300 and $248 \mathrm{~nm}$. These data suggested that 1 has the same absolute configurations, $2 S, 3 R, 11 S$ and $14 R$, as $2 .{ }^{13}$

SOAT inhibitory activity of $\mathbf{1}$ and $\mathbf{2}$ was investigated in the enzyme assay using microsomes prepared from SOAT1- and SOAT2expressing $\mathrm{CHO}$ (hereafter referred to as SOAT1-CHO and SOAT2CHO, respectively) cells. ${ }^{14}$ As summarized in Table 3, 1 and 2 are SOAT inhibitors rather selective toward SOAT2 isozyme in the enzyme assay. Furthermore, the SOAT inhibition was evaluated in a cell-based assay using SOAT1- and SOAT2-CHO cells. ${ }^{14}$ As shown in Table 3, 2 inhibited CE synthesis with an $\mathrm{IC}_{50}$ value of $0.45 \mu \mathrm{m}$ in SOAT2-CHO cells, and it became clear that 2 is a SOAT2-selective inhibitor with a selective index (SI) value of 62 in the cell-based assay. However, 1 showed no inhibition of SOAT1 and SOAT2 at $22 \mu \mathrm{M}$. It might be that 1 cannot penetrate $\mathrm{CHO}$ cells. Shinohara et al. ${ }^{15}$ reported that structurally related gypsetin (3), produced by the fungus Nannizzia gypsea var. incurvata IFO9228, inhibited rat liver microsomal SOAT activity $\left(\mathrm{IC}_{50}, 18 \mu \mathrm{M}\right)$ and cholesteryl ester synthesis in macrophage $\mathrm{J} 774\left(\mathrm{IC}_{50}, 0.65 \mu \mathrm{M}\right)$. Now it is known that $\mathrm{J} 774$ cells 
Table $2{ }^{1} \mathrm{H}$ and ${ }^{13} \mathrm{C}$ NMR chemical shifts of $1\left(600 \mathrm{MHz}\right.$ for ${ }^{1} \mathrm{H}$, $150 \mathrm{MHz}$ for ${ }^{13} \mathrm{C}$ )

\begin{tabular}{|c|c|c|c|}
\hline \multirow[b]{2}{*}{ Position } & \multicolumn{3}{|c|}{1} \\
\hline & $\delta_{C}(p . p . m .)^{\mathrm{a}}$ & $\delta_{H}(\text { p.p.m. })^{b}$, multi, J in $\mathrm{Hz}$ & $H M B C$ \\
\hline 1 & - & $5.06, \mathrm{sd}, 1.0$ & $C-3,9$ \\
\hline 2 & 77.7 & $5.55, \mathrm{~s}$ & $\mathrm{C}-8,9,11,13,3^{\prime}$ \\
\hline 3 & 61.6 & - & - \\
\hline 4 & 125.1 & $7.14^{c}$ & $C-3,6,8$ \\
\hline 5 & 118.9 & $6.76, \mathrm{td}, 7.5,0.8$ & $C-4,7,9$ \\
\hline 6 & 128.9 & $7.11^{\mathrm{c}}$ & $C-4,8$ \\
\hline 7 & 109.2 & $6.61, d, 7.5$ & $C-5,9$ \\
\hline 8 & 149.9 & - & - \\
\hline 9 & 128.9 & - & - \\
\hline 10 & 36.0 & $\begin{array}{c}2.42, \mathrm{t}, 12.0 \\
2.51, \mathrm{dd}, 12.5,6.0\end{array}$ & $\mathrm{C}-2,3,9,11,16,3^{\prime}$ \\
\hline 11 & 59.0 & $3.91, \mathrm{dd}, 11.5,6.0$ & C-10, 16 \\
\hline 12 & - & - & - \\
\hline 13 & 166.0 & - & - \\
\hline 14 & 54.6 & $4.30, d, 10.5$ & $\mathrm{C}-13,17,18$ \\
\hline 15 & - & $5.69, \mathrm{~s}$ & $\mathrm{C}-11,13,14,16,17$ \\
\hline 16 & 168.9 & - & - \\
\hline 17 & 27.0 & $\begin{array}{c}2.97, \mathrm{dd}, 10.8,11.0 \\
3.74, \mathrm{dd}, 4.0\end{array}$ & $\mathrm{C}-13,14,18,19,26$ \\
\hline 18 & 109.7 & - & - \\
\hline 19 & 123.2 & $7.08, \mathrm{sd}, 2.0$ & $\mathrm{C}-17,18,21,26$ \\
\hline 20 & - & $8.19, \mathrm{~s}$ & $\mathrm{C}-18,19,21,26$ \\
\hline 21 & 136.6 & - & - \\
\hline 22 & 115.5 & $7.38, d, 8.5$ & C-23, 24, 26 \\
\hline 23 & 122.9 & $7.22, \mathrm{td}, 7.5,1.0$ & C- $22,24,25$ \\
\hline 24 & 120.1 & $7.12^{\mathrm{c}}$ & $C-22,23,26$ \\
\hline 25 & 118.4 & $7.55, d, 8.0$ & $\mathrm{C}-21,23,26$ \\
\hline 26 & 126.6 & - & - \\
\hline $1^{\prime}$ & 114.5 & $\begin{array}{l}5.08, \mathrm{dd}, 13.5,1.2 \\
5.12, \mathrm{dd}, 10.5,1.0\end{array}$ & $C-2^{\prime}, 3^{\prime}$ \\
\hline $2^{\prime}$ & 143.5 & $5.97, \mathrm{dd}, 18.0,10.5$ & $\mathrm{C}-3,1^{\prime}, 3^{\prime}, 4^{\prime}, 5^{\prime}$ \\
\hline $3^{\prime}$ & 40.8 & - & - \\
\hline $4^{\prime}$ & 22.8 & $1.01, \mathrm{~s}$ & $\mathrm{C}-3,1^{\prime}, 2^{\prime}, 3^{\prime}, 5^{\prime}$ \\
\hline $5^{\prime}$ & 22.4 & $1.11, \mathrm{~s}$ & $C-3,1^{\prime}, 2^{\prime}, 3^{\prime}, 4^{\prime}$ \\
\hline
\end{tabular}

aChemical shifts are shown with reference to $\mathrm{CDCl}_{3}$ as $\delta 77.0$.

${ }^{b}$ Chemical shifts are shown with reference to $\mathrm{CDCl}_{3}$ as $\delta 7.26$.

'Signals are overlapping.

exclusively express SOAT1 and rat liver mainly expresses SOAT2. Therefore, it will be worth testing 3 in our assay system to make the SOAT selectivity clear.

A number of indoline alkaloid-containing diketopiperazines carry a prenyl moiety at C3. For example, amauromine (2), gypsetin (3), epiamauromine, ${ }^{16}$ roquefortine $\mathrm{C}^{17}$ and fructigenines $\mathrm{A}$ and $\mathrm{B}^{18}$ were discovered as fungal metabolites, mainly produced by Penicillium and Aspergillus. In this study, we discovered $\mathbf{1}$ and $\mathbf{2}$ from a marine-derived actinomycete, Nocardiopsis sp. KM2-16. It will be worth comparing the biosynthetic genes from fungal and actinomycete strains.

\section{CONFLICT OF INTEREST}

The authors declare no conflict of interest.

\section{ACKNOWLEDGEMENTS}

We thank Ms Noriko Sato and Dr Kenichiro Nagai (School of Pharmaceutical Sciences, Kitasato University) for measurements of NMR spectra and MS data.

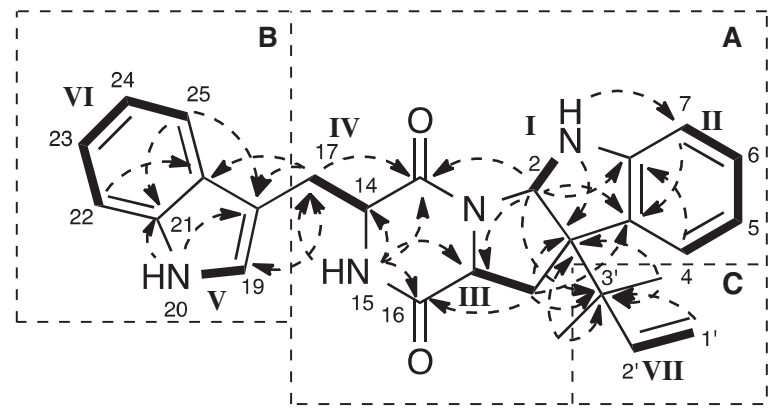

${ }^{1} \mathrm{H}^{-1} \mathrm{H}$ COSY

Figure 2 Key cross-peaks observed in ${ }^{1} \mathrm{H}^{1}{ }^{1} \mathrm{H}$ COSY and ${ }^{1} \mathrm{H}-{ }^{13} \mathrm{C}$ HMBC experiments of 1 .

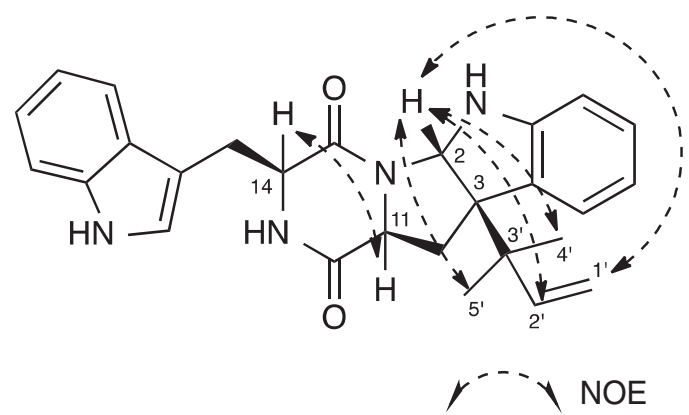

Figure 3 Key NOE experiment of $\mathbf{1}$.

Table 3 Effects of 1 and 2 on SOAT isozymes in cell-based and enzyme-based assays

\begin{tabular}{|c|c|c|c|c|c|c|c|}
\hline \multirow[t]{3}{*}{ Compound } & \multicolumn{3}{|c|}{ Enzyme-based } & \multicolumn{3}{|c|}{ Cell-based } & \multirow{3}{*}{$\begin{array}{c}\text { Cytotoxicity } \\
{ }^{a} \\
1 C_{50}(\mu \mathrm{M})\end{array}$} \\
\hline & \multicolumn{2}{|c|}{$1 C_{50}(\mu \mathrm{M})$} & \multirow[b]{2}{*}{$S P^{p}$} & \multicolumn{2}{|c|}{$I C_{50}(\mu \mathrm{M})$} & \multirow[b]{2}{*}{ SI } & \\
\hline & SOAT1 & SOAT2 & & SOAT1 & SOAT2 & & \\
\hline 1 & $>57$ & 21 & $>2.7$ & $>22$ & $>22$ & 1 & $>22$ \\
\hline 2 & 22 & 1.2 & 18 & $>28$ & 0.45 & $>62$ & $>28$ \\
\hline
\end{tabular}

This work was supported by a Grant-in-aid for Scientific Research (A) 26253009 from the Ministry of Education, Culture, Sports, Science and Technology, Japan (to HT).

1 Chang, C. C., Huh, H. Y., Cadigan, K. M. \& Chang, T. Y. Molecular cloning and functional expression of human acyl-coenzyme A:cholesterol acyltransferase cDNA in mutant Chinese hamster ovary cells. J. Biol. Chem. 268, 20747-20755 (1993).

2 Anderson, R. A. et al. Identification of a form of acyl-CoA:cholesterol acyltransferase specific to liver and intestine in nonhuman primates. J. Biol. Chem. 273, 26747-26754 (1998)

3 Cases, S. et al. ACAT-2, a second mammalian acyl-CoA:cholesterol acyltransferase. Its cloning, expression, and characterization. J. Biol. Chem. 273, 26755-26764 (1998).

4 Oelkers, P., Behari, A., Cromley, D., Billheimer, J. T. \& Sturley, S. L. Characterization of two human genes encoding acyl coenzyme A:cholesterol acyltransferase-related enzymes. J. Biol. Chem. 273, 26765-26771 (1998).

5 Yagyu, $\mathrm{H}$. et al. Absence of ACAT-1 attenuates atherosclerosis but causes dry eye and cutaneous xanthomatosis in mice with congenital hyperlipidemia. J. Biol. Chem. 275 21324-21330 (2000). 
6 Accad, M. et al. Massive xanthomatosis and altered composition of atherosclerotic lesions in hyperlipidemic mice lacking acyl CoA:cholesterol acyltransferase 1. J. Clin. Invest. 105, 711-719 (2000).

7 Fazio, S. et al. Increased atherosclerosis in LDL receptor-null mice lacking ACAT1 in macrophages. J. Clin. Invest. 107, 163-171 (2001)

8 Buhman, K. K. et al. Resistance to diet-induced hypercholesterolemia and gallstone formation in ACAT2-deficient mice. Nat. Med. 6, 1341-1347 (2000).

9 Willner, E. L. et al. Deficiency of acyl CoA:choletsterol acyltransferase 2 prevents atherosclerosis in apolipoprotein E-deficient mice. Proc. Natl. Acad. Sci. USA 100, 1262-1267 (2003).

10 Takase, S. et al. Amauromine, a new vasodilator. Taxonomy, isolation and characterization. J. Antibiot. 37, 1320-1323 (1984).

11 Yin, W. B., Xie, X. L., Matuschek, M. \& Li, S. M. Reconstruction of pyrrolo[2,3-b]indoles carrying an alpha-configured reverse C3-dimethylallyl moiety by using recombinant enzymes. Org. Biomol. Chem. 8, 1133-1141 (2010).

12 Yin, W. B., Grundmann, A., Cheng, J. \& Li, S. M. Acetylaszonalenin biosynthesis in Neosartorya fischeri. Identification of the biosynthetic gene cluster by genomic mining and functional proof of the genes by biochemical investigation. J. Biol. Chem. 284, 100-109 (2009).
13 Takase, S., Kawai, Y., Uchida, I., Tanaka, H. \& Aoki, H. Structure of amauromine, a new hypotensive vasodilator produced by Amauroascus sp. Tetrahedron 41, 3037-3048 (1985).

14 Ohshiro, T., Rudel, L. L., Ōmura, S. \& Tomoda, H. Selectivity of microbial acyl-CoA: cholesterol acyltransferase inhibitors toward isozymes. J. Antibiot. 60, 43-51 (2007).

15 Shinohara, C., Hasumi, K., Takei, Y. \& Endo, A. Gypsetin, a new inhibitor of acyl-CoA: cholesterol acyltransferase produced by Nannizzia gypsea var. incurvata IF09228. I. Fermentation, isolation, physico-chemical properties and biological activity. J. Antibiot. 47, 163-167 (1993).

16 De Guzmann, F. S., Gloer, J. B., Wicklow, D. T. \& Dowd, P. F. New diketopiperazine metabolites from the sclerotia of Aspergillus ochraceus. J. Nat. Prod. 55, 931-939 (1992).

17 Scott, P. M. \& Kennedy, P. C. Analysis of blue cheese for roquefortine and other alkaloids from Penicillium roqueforti. J. Agric. Food Chem. 24, 865-868 (1976).

18 Arai, K., Kimura, K., Mushiroda, T. \& Yamamoto, Y. Structures of fructigenines A and B, new alkaloids isolated from Penicillium fructigenum TAKEUCHI. Chem. Pharm. Bull. 37, 2937-2939 (1989).

19 Ohte, S. et al. Dinapinones, novel inhibitor of triacylglycerol synthesis in mammalian cells, produced by Penicillium pinophilum FKI-3864. J. Antibiot. 64, 489-494 (2011). 